\title{
Images in Clinical Medicine
}

Wien Klin Wochenschr (2006) 118/23-24: 738

DOI 10.1007/s00508-006-0713-z

WIENER KLINISCHE

WOCHENSCHRIFT

The Middle European Journal

of Medicine

(C) Springer-Verlag 2006

\section{Traumatic kidney injury before and after reconstruction}

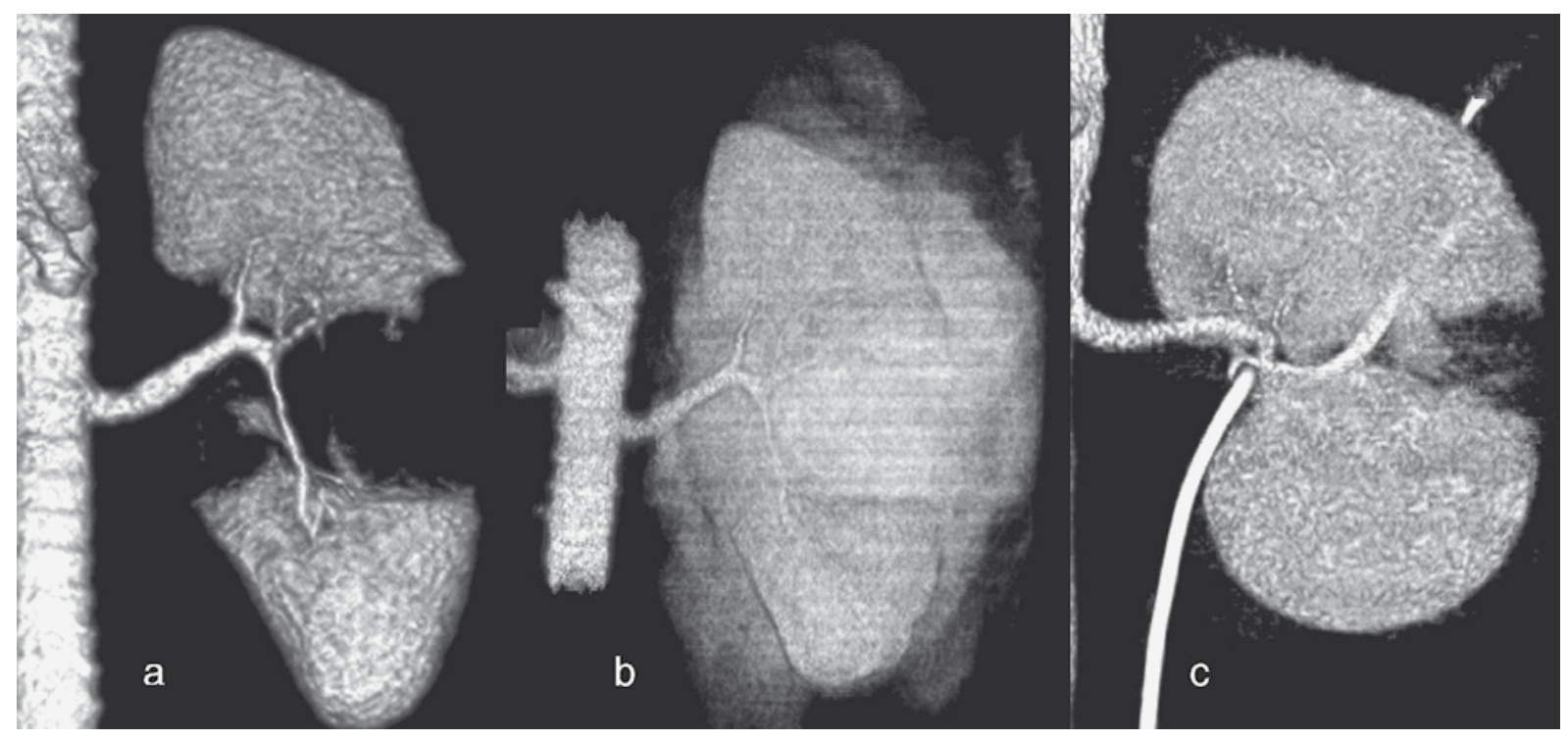

Three-dimensional (3D) angio-computed tomography has refined strategic planning in reconstructive surgery after trauma [1]. We describe a dramatic case of grade IV renal trauma after a skiing accident in a 32-year-old man [2]. After losing control he had crashed against a snowmaking machine, fracturing his left twelfth rib and the transverse process of his third lumbar vertebra, and thereby rupturing his kidney. After emergency triage [3], a 3D-reconstruction of the arterial tree to the traumatized kidney demonstrated stretched out arteries in the hilum supplying both halves (Fig. 1a). A big hematoma filled the perinephric space (Fig. 1b). Both halves were separated by hematoma, but the parenchyma was still perfused. These images motivated us to attempt a complete reconstruction of the kidney. After informed consent was obtained the kidney was explored through a left flank incision. The perirenal hematoma was removed and vascular control achieved, then the lacerated renal veins were reconstructed. A nephrostomy was placed in the upper half of the kidney and a pigtail catheter in the lower half (Fig. 1c). The collecting system was approximated and the kidney was placed in a vicryl bag. At one and a half years follow-up the kidney functions well and is the same size as the contralateral kidney.

Performing a 3D-arterial tree reconstruction of a traumatized kidney allows accurate evaluation of the renal parenchyma. In grade IV renal injuries this allows for reconstruction planning in cases where exploration is indicated.

Peter Rehder, Tilko Müller, and Alexandre E. Pelzer

\section{Acknowledgements}

Department of Radiology I, Medical University Innsbruck for the 3D-angio-computer tomogram reconstruction.

\section{References}

1. Santucci R A, Wessells H, Bartsch G, Descotes J, Heyns C F, McAninch J W, Nash P, Schmidlin F (2004) Evaluation and management of renal injuries: consensus statement of the renal trauma subcommittee. BJU International 93 (7): 937-954

2. Moore EE, Shackford SR, Pachter HL, et al (1989) Organ injury scaling: spleen, liver, and kidney. J Trauma 29: 16641666

3. Carlin BI, Resnick MI (1995) Indications and techniques for urologic evaluation of the trauma patient with suspected urologic injury. Semin Urol 13: 9-24

Key words: Kidney trauma, reconstruction, angio-computed tomography.

Correspondence: Peter Rehder, MD, Department of Urology, Medical University Innsbruck, Anichstraße 35, 6020 Innsbruck, Austria, E-mail: peter.rehder@uibk.ac.at 